\title{
A clinical study of ectopic pregnancy in a tertiary care centre in Hubli
}

\author{
Swetha Dama*, Amitha Kamat
}

Department of Obstetrics and Gynaecology, Karnataka Institute of Medical Sciences, Hubli, Karnataka India

Received: 10 February 2017

Accepted: 07 March 2017

*Correspondence:

Dr. Swetha Dama

E-mail: dr.swethadama@gmail.com

Copyright: (C) the author(s), publisher and licensee Medip Academy. This is an open-access article distributed under the terms of the Creative Commons Attribution Non-Commercial License, which permits unrestricted non-commercial use, distribution, and reproduction in any medium, provided the original work is properly cited.

\begin{abstract}
Background: To evaluate the burden of ectopic pregnancies in our hospital over the period of one year and to evaluate the risk factors, mode of intervention and outcomes of those cases.

Methods: A retrospective analysis was conducted in Karnataka Institute of Medical Sciences, Hubli over the period of one year from January 2015 to December 2015. All patients admitted with a diagnosis of ectopic pregnancy, either ruptured or unruptured were included in the study. Their history, risk factors, outcome and complications were also evaluated in detail.

Results: 40 patients with diagnosis of ectopic pregnancy were admitted, yielding to an incidence of 3.76/1000. Most patients presented to our hospital in a state of shock. 26(65\%) were ruptured, $10(25 \%)$ were unruptured and $4(10 \%)$ were chronic ectopic pregnancies. 39 cases were managed by laparotomy and one patient by conservative method using methotrexate. Most common risk factor noted in our study was history of tubal sterilization, noted among $12(30 \%)$ women. No mortality was noted in our study.

Conclusions: Ectopic pregnancy is a significant cause of morbidity and mortality in first trimester. High degree of suspicion and early detection can prevent a great degree of morbidity among women, especially in women with prior tubal sterilization procedure.
\end{abstract}

Keywords: Ectopic pregnancy, Laparotomy, Ruptured ectopic, Salpingectomy, Tubal sterilisation

\section{INTRODUCTION}

Ectopic pregnancy is defined as any intra- or extrauterine pregnancy in which the fertilised ovum implants at an aberrant site which is in conducive to its growth and development. ${ }^{1}$ It is a condition of immense gynaecological importance, particularly in developing world, because of high morbidity and occasionally mortality associated with it. When ruptured, ectopic pregnancy is a true medical emergency. Most of the cases present late with rupture and hemodynamic compromise. ${ }^{2}$ It has also been associated with recurrence and impairment of subsequent fertility. ${ }^{3}$

The aetiology of ectopic pregnancy is not well understood. Multiple risk factors have been associated with ectopic pregnancy. Pelvic inflammatory disease, puerperal sepsis, post-abortion sepsis, appendicitis and the use of intra-uterine contraceptive devices have been identified as major risk factors. Other factors include age more than 35yrs, tubal/pelvic surgeries, endometritis, exposure to diethylstilboestrol in utero, use of progesterone only pills, conception following induction of ovulation, history of infertility. However, ectopic pregnancy can also occur without any obvious risk factors. ${ }^{4}$

Patients with an ectopic pregnancy commonly present with abdominal pain and vaginal bleeding between 6-10 weeks' gestation. ${ }^{5,6}$ The diagnosis of ectopic pregnancy has become more frequent during last decade. Early diagnosis reduces the risk of tubal rupture and allows more conservative medical treatments to be employed. ${ }^{7}$ This study was conducted to evaluate the burden of ectopic pregnancies in our hospital and to analyze their clinical profile and outcomes. 


\section{METHODS}

Our institution is a referral centre for Dharwad district, as well as surrounding 4 districts and has a delivery rate of about 10,000 per year. This was a retrospective study of one year at Karnataka Institute of Medical Sciences, Hubli, during the period of January 2015- December 2015. The case sheets of patients with ectopic pregnancies were recovered from labour ward and obstetric ICU. Analysis of history to reveal the presence of any risk factors, physical examination findings, diagnosis whether ruptured or un-ruptured ectopic, mode of treatment, interventions done, post-operative recovery and complications were studied.

\section{RESULTS}

Between January 2015 to December 2015, there were
10644 deliveries. There were 40 cases of ectopic pregnancy managed in our hospital yielding an incidence of 3.76/1000. Most of them were multi-gravidae, many with history of tubectomy. Among the 40 patients 10 were unruptured ectopic pregnancies, 4 were chronic ectopic pregnancies and the rest 26 were rupture with acute onset of symptoms. Of them 10 patients were admitted to the hospital in state of shock.

Risk factors identified in our study-2 (5\%) had history of previous ectopic pregnancy, $6(15 \%)$ had history of abdominal surgeries including caesarean section, and one patient had undergone laparotomy for previous ectopic, $14(35 \%)$ had tubal surgeries, 3 (7.5\%) following infertility treatment and $3(7.5 \%)$ had history of dilatation and curettage following abortion (Table 1).

Table 1: Risk factors for ectopic pregnancy.

\begin{tabular}{|lll|}
\hline Risk factor & Number & Percent \\
\hline Previous history of ectopic pregnancy & 02 & 05 \\
\hline History of pelvic inflammatory disease & 04 & 10 \\
\hline History of previous abdominal surgeries & & 12.5 \\
\hline History of caesarean section & 05 & 2.5 \\
\hline Others & 01 & 30 \\
\hline History of tubal surgeries & 12 & 05 \\
\hline Tubectomy & 02 & 7.5 \\
\hline Recanalization & 03 & 7.5 \\
\hline Infertility treatment & 03 & \\
\hline History of abortion(induced/spontaneous) & & \\
\hline
\end{tabular}

Two patients with previous history of ectopic pregnancy were admitted with features of hypovolemic shock following rupture of tubal ectopic. ${ }^{8}$ One patient had history of previous ectopic pregnancy in the same tube as the index pregnancy and the other patient suffered from rupture of tubal ectopic in the contralateral fallopian tube. Both patients were now managed by emergency laparotomy and salpingectomy.

12 women who previously had undergone sterilization procedures presented with ectopic pregnancies and 2 patients following tubal recanalization. One of the patients who underwent recanalization had history of previous 2 caesarean sections with abdominal tubectomy. Due to loss of both her off springs, recanalization procedure was performed following which she developed post-operative wound infection and underwent secondary suturing of the gaped wound. Within a span of 1.5 years she presented to our hospital in shock with a diagnosis of ruptured ectopic pregnancy. 3 women had a history of infertility treatment with clomiphene citrate given for ovulation induction (Table 1). ${ }^{9}$
Commonest site of ectopic pregnancy was found to be in ampullary region of the tube, 4 women had ectopic at tubectomy site and 4 women had ovarian pregnancy and 1 interstitial pregnancy.

There were no cervical or abdominal ectopic pregnancies in our study. 3 were cornual pregnancies, 3 were located at the fimbrial end and 2 were tubal abortions (Table 2).

Table 2: Site of ectopic pregnancies on laparotomy.

\begin{tabular}{|lll|}
\hline Site of pregnancy & Number & Percent \\
\hline Ampulla & 15 & 32.5 \\
\hline Cornu & 3 & 7.5 \\
\hline Isthmus & 4 & 10 \\
\hline Isthmoampullary & 4 & 10 \\
\hline Fimbria & 3 & 7.5 \\
\hline Ovarian & 4 & 10 \\
\hline Tubectomy site & 4 & 10 \\
\hline Interstitial & 1 & 2.5 \\
\hline Tubal abortion & 2 & 5 \\
\hline
\end{tabular}


The gestational age at rupture varied from 6 weeks to 21 weeks depending on the site 4 of ectopic. The details are depicted in (Table 3).

Table 3: Site of pregnancy and its correlation with the gestation age.

\begin{tabular}{|ll|}
\hline Site of ectopic & \\
\hline Ampulla & $7-11$ weeks \\
\hline Fimbria & $7-8$ weeks \\
\hline Cornua & $16-21$ weeks \\
\hline Isthmus & $6-7$ weeks \\
\hline Ovarian & $6-10$ weeks \\
\hline Tubectomy site & $7-17$ weeks \\
\hline Interstitial & 6 weeks \\
\hline
\end{tabular}

Most of the patients underwent either total or partial salpingectomy and excision of cornu was done in 3 (7.5\%) women (Table 4). For ovarian ectopic pregnancy, ovariotomy was performed in $3(7.5 \%)$ patients and wedge resection in one patient. One patient with unruptured tubal ectopic was initially managed by administration of methotrexate. Following the second dose, she was taken up for laparotomy for rupture of the ectopic. One other patient in our study was managed by medical method i.e., by methotrexate. Regular follow-up showed resolution of ectopic pregnancy.

Table 4: Mode of intervention.

\begin{tabular}{|ll|}
\hline Procedure performed & Number \\
\hline Partial salpingectomy & 13 \\
\hline Total salpingectomy & 13 \\
\hline Fimbriectomy & 3 \\
\hline Excision of cornu & 3 \\
\hline Ovariotomy & 3 \\
\hline Wedge resection of ovary & 1 \\
\hline
\end{tabular}

Most of the patients with ruptured ectopic pregnancy who underwent laparotomy required blood transfusion. Complications noted after management were minimal, except in two patients, who required monitoring in ICU with inotropic support and mechanical ventilation. One among them developed pneumonia post-operatively. No other complications or mortality was noted in our study. Average amount blood transfused was 2 units per patient. $90 \%$ of patients received blood transfusion

\section{DISCUSSION}

Ectopic pregnancy is the most common cause of death in the first trimester of pregnancy in developing countries. Most of the cases are tubal ectopic, less that $1 \%$ are ovarian pregnancies which fulfil Spiegelberg criteria; 1) the tube and fimbria must be intact and separate from ovary 2) gestational sac must occupy the normal position of the ovary 3 ) the sac must be connected to the uterus by the ovarian ligament. 4) Ovarian tissue must be demonstrable in the walls of the sac. ${ }^{10}$
The incidence of ectopic pregnancy in our study is$3.75 / 1000$ deliveries. Incidence of ectopic was found to be highest among multiparous women, and surprisingly 12 women, among 40, in our study had history of tubectomy. History of previous ectopic pregnancy predisposes a woman for recurrence, which was noted in 2 women. History of pelvic inflammatory disease is very difficult to elicit, since most of them have a subclinical infection and do not visit a health care centre for treatment. Lower abdominal pain was the most common clinical presentation in our subjects. Other symptoms included amenorrhea, spotting per vaginum, shouder-tip pain, vomiting. These occurred as a result of ruptured ectopic pregnancy and can be a lifethreatening complication without timely intervention.

Patients with ruptured ectopic gestation, in our study presented in a state of shock, hypovolemia, hypotension, tachycardia. Diagnosis was made by clinical examination and use of urine pregnancy tests and paracentesis/culdocentesis. Ultrasonography mainly was helpful in diagnosis in suspected cases of ectopic pregnancy and in hemodynamically stable patients.

The commonest site of ectopic pregnancy in our study was the ampullary region of the fallopian tube. Gestation age in these patients varied from 7-11weeks. Severe blood loss and post-operative morbidity was noted in cornual pregnancy, gestation age in whom varied from 16-21weeks. Cornual pregnancies usually rupture later than tubal pregnancies because the myometrium is more distensible than the fallopian tube. Increased vascularity associated with cornual pregnancy is more likely to result in a catastrophic haemorrhage and death. ${ }^{11}$

Recurrent ectopic pregnancy is more likely to present at an earlier gestation age, with lower $\beta$-hcg and significantly less hemoperitoneum8. Universally women treated for ectopic pregnancy are informed approximately $10 \%$ risk of recurrence and are advised to have an early pregnancy ultrasound. Women with recurrent ectopic pregnancy were significantly more likely to have contralateral tubal pathology and there always has been a debate as to what type of surgery should be performed in women with recurrent ectopic.

\section{CONCLUSION}

High index of suspicion is required for diagnosis of ectopic pregnancy. Most of the cases in our study were diagnosed clinically and with the use of ultrasonography. The recent trend of conservative management of ectopic pregnancy did not hold true in our hospital setting, since most of the cases were delayed referrals with rupture and in a state of shock.

Funding: No funding sources Conflict of interest: None declared

Ethical approval: The study was approved by the Institutional Ethics Committee 


\section{REFERENCES}

1. Gaddagi RA, Chandrashekar AP. A Clinical study of ectopic pregnancy. JCDR. 2012;6:867-9.

2. Panti A, Ikechukwu NE, lukmanOO, YakubuA, Egondu SC, Tanko BA. Ectopic pregnancy at UsmanuDanfodiyo University Teaching Hospital Sokoto: a ten year review. Ann Niger Med. 2012;6(2):87-91.

3. Abdul FI. Ectopic pregnancy in Ilorin: a review of 278 cases. Niger J Med. 2000;9(3):92-6.

4. Gharoro EP, Igbafe AA. Ectopic pregnancy revisited in Benin City, Nigeria:analysis of 152 cases. ActaObstetGynecol Scand. 2002;81(12):1139-43.

5. Walker JJ. Ectopic pregnancy. Clin Obstet Gynecol. 2007;50:89-99.

6. Shetty S, Shetty A. A Clinical study of ectopic pregnancies in tertiary care hospital of Mangalore, India. Innovative Journal of Medical and Health Science. 2014;4(1).

7. Wan S, Xiang Y, Fang W, Huang D. The effect of methotrexate in combination with mifepristone on ectopic pregnancy: a meta-analysis. Int $\mathrm{J}$ Clin Exp Med. 2016;9(8):14990-5003.

8. Hurrell A, Reeba O, Funlayo O. recurrent ectopic pregnancy as a unique clinical subgroup: a case control study. SpringerPlus. 2016;5910:1.

9. Hachem LeEI, Stein DE, Keltz MDM, Lederman MA Ovarian Heterotropic Pregnancy after Ovulation Induction with Clomiphene Citrate. Gynaecol Obstrtric. 2011;1;107

10. O.Speigelberg, "ZurCasuistik der ovarialschwanger schaft", Archiv fur Gynakologie. 1878;13(1)7379,1878 .

11. B Mohamed, A Radhouane, G Nizar, M Lotfi, R Rashouane. A Ruptured Cornual Ectopic Pregnancy At 18 weeks' Gestation: A Case Report. The Internet Journal of Gynecology and Obstetrics. 2012;16:3.

Cite this article as: Dama S, Kamat A. A clinical study of ectopic pregnancy in a tertiary care centre in Hubli. Int J Reprod Contracept Obstet Gynecol 2017;6:1566-9. 